\title{
Efficiency evaluation of water production from the atmospheric air in Vietnam
}

\author{
Van Hung Tran ${ }^{1,2,}$, Thanh Nhan Phan ${ }^{1,2}$, Nikola Kaloyanov ${ }^{3}$, and Momchil Vassilev ${ }^{3}$ \\ ${ }^{1}$ Ho Chi Minh City University of Technology (HCMUT), 268 Ly Thuong Kiet Street, District 10, Ho \\ Chi Minh City, Vietnam \\ ${ }^{2}$ Vietnam National University Ho Chi Minh City, Linh Trung Ward, Thu Duc District, Ho Chi Minh \\ City, Vietnam \\ ${ }^{3}$ Technical University of Sofia, Power Engineering and Power Machines Department, 8 Kliment \\ Ohridski Blvd., 1000 Sofia, Bulgaria
}

\begin{abstract}
The analysis of extracting potable water from the humid ambient air has been done by using the model of vapor-compression refrigeration (VCR) system for the case study in Vietnam. The temperature and relative humidity of moist air in Danang province in Vietnam were recorded for a whole year. The typical day in each month of year with detailed values of temperature and relative humidity for 24 hours were presented and used to identify the production of water from the air. The results show that, the temperature at the outlet of air stream throughout evaporator of VCR system is about $13^{\circ} \mathrm{C}$ in which the energy consumption to produce 1 liter of water is lowest. Besides, the electricity consumption cost in Vietnam varies in a day with various tariffs: at the peak load, medium load and low load, depends on the time of the day. The production price for one liter of water is also considered and working plans are proposed for the system by the time of the day.
\end{abstract}

\section{Introduction}

The lack of potable water supply is a matter of great concern not only in Vietnam but also in many countries around the World. In previous studies, various methods for producing water from natural sources such as the distillation of sea water, or condensing the water vapor in the air from vapor into liquid by absorbing heat to make that processes occur, or producing water from the humid air by using air conditioning system are analyzed [1]-[6]. However, this is still a burning issue, so that this problem was investigated very early by $B$. Hellstrom [2] in 1969 about the experimental extracted water from a commercial air conditioning plant. In $1991 \mathrm{~S}$. Elshamarka [4] focused on the potable water production used in solar air conditioning systems for solar house which worked on the absorption heat pump cycle in the Hurgada area on the Red Sea coast. The issue has drawn a lot of attention from researchers all over the world in recent years. In 2011, T. Anbarasu and S. Pavithra [3] designed and fabricated a system with UV light and Ozone water purification producing 99\% pure drinking water. Magrini et al. [1] in 2015 combined HVAC system for dual

\footnotetext{
* Corresponding author: tvhung@hcmut.edu.vn
} 
purpose of producing water and air conditioning. They also presented a case study in a hotel at a sub-tropical arid climate. Furthermore, a new technological method for producing water from air was introduced in Joshi et al. [5] in 2017; in which, the thermoelectric fresh water generator with the thermoelectric cooling effect was carried out. They designed and operated their experiments with $81 \%$ rising of water generation from the air if they placed internal heat sink compared with no heat sink condition. Du Runze et al. [6] in 2020 presented a portable solar-photovoltaic atmospheric water generator which was built for their experiments. This issue is increasingly urgent and important especially for the arid area or the places where water is needed.

The atmospheric air contains a huge amount of water vapor which can be used as a source for liquid water production. The atmospheric water generator (AWG) is an environmentally friendly technique which is also a safe and visible approach for sustainable water supply. The generator is considered on the operating temperature of evaporator of refrigeration system, the efficiency of water production according to energy consumption, and also the cost of producing one liter of water. These elements vary based on: the weather differences of each province in Vietnam; the properties of atmospheric air change from hour to hour during the day; and the influence of the policy on electric consumption in Vietnam (different tariffs for different periods of the day). Therefore, this is a very interesting case study for our research which employed available monthly and daily weather data to analyze and represent in this paper.

\subsection{Introducing the Weather conditions of Danang Province, Vietnam:}

Weather data for Danang Province in Vietnam is taken from the Vietnam Building code, Natural Physical and Climatic data for construction [7]. In Figure 1, the 3D plot of average data recorded for temperature and relative humidity in a certain day describes each month of the year.
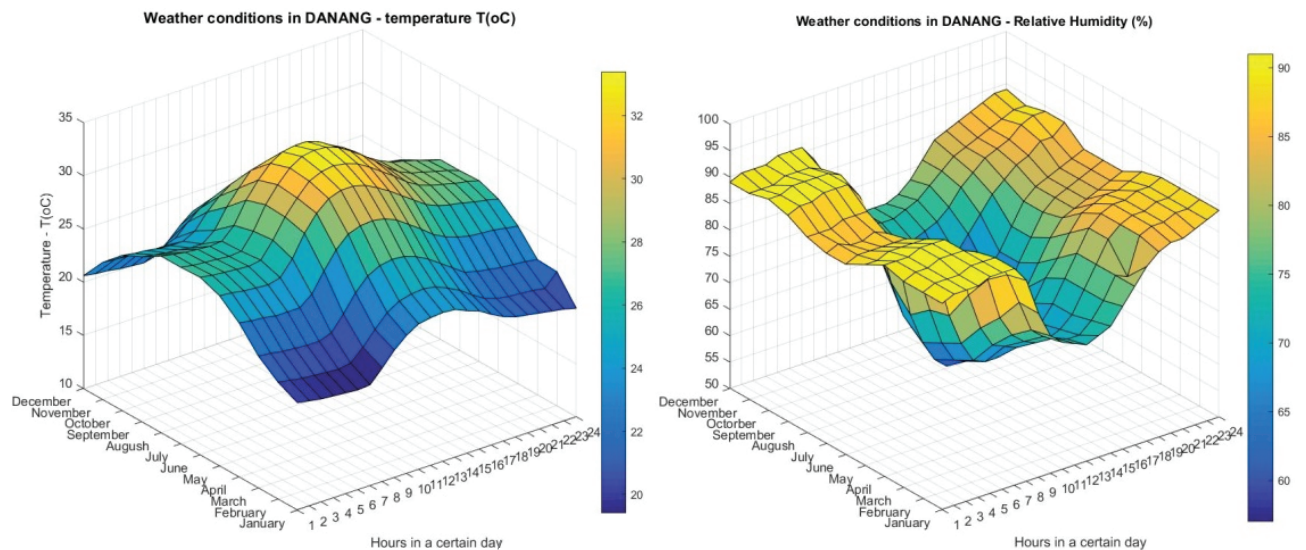

Fig. 1. Temperature and relative humidity of air, plot in $3 \mathrm{D}-\mathrm{t}\left[{ }^{\circ} \mathrm{C}\right]$ and $\varphi[\%]$.

It is clearly observed that July is the hottest month of the year but also it reaches the lowest point of relative humidity. In the daytime from 9:00 to 16:00 the temperature is over $30^{\circ} \mathrm{C}$ during summer season (May to September), while the relative humidity is around 57 to $90 \%$. Conversely, during the sunset and at night, the temperature drops and remains within the range of 25 to $28^{\circ} \mathrm{C}$ (even during the sunrise).

The temperature, relative humidity, humidity ratio (specific humidity) and specific enthalpy for a day in July are presented in Figure 2. 

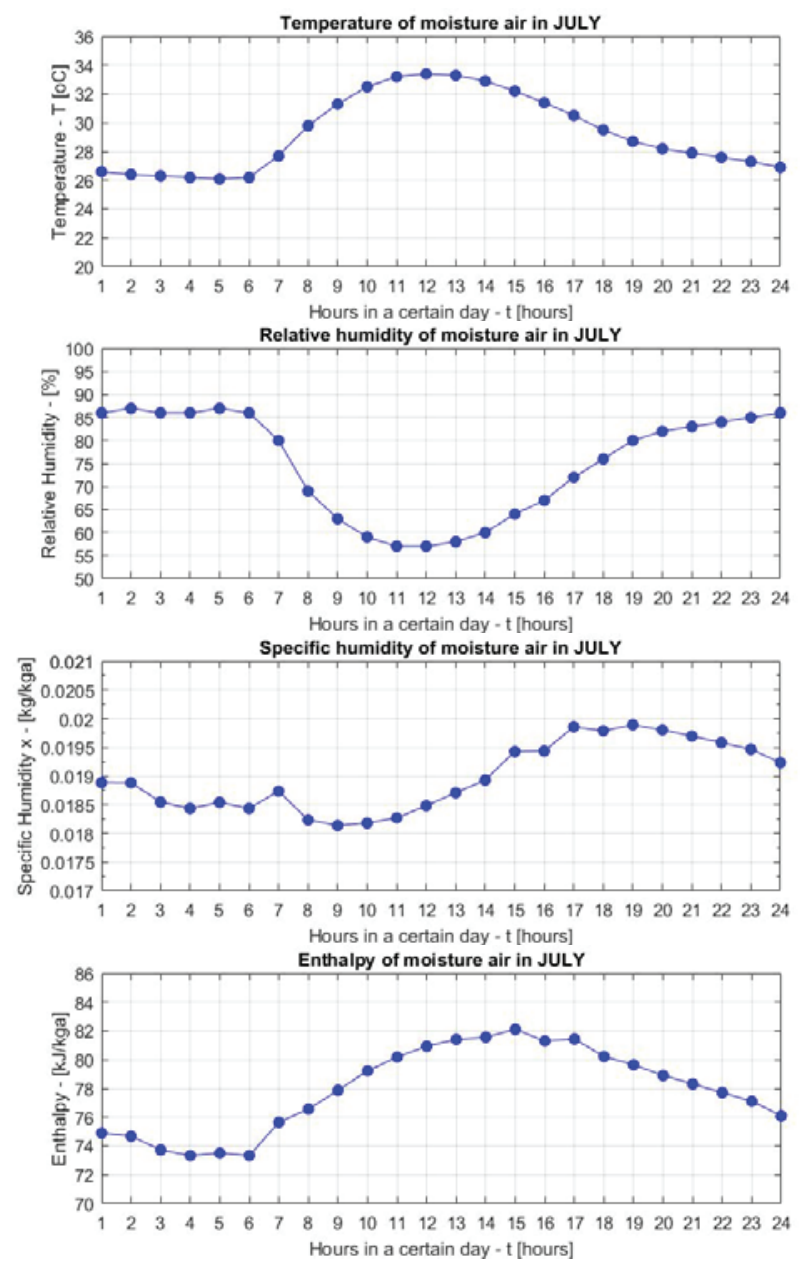

Fig. 2. The properties of moist air during a day in July.

The temperature is from 26 to $34^{\circ} \mathrm{C}$, the relative humidity is within the range of 57 to $87 \%$ while the specific humidity is from 0.0182 to $0.02 \mathrm{~kg}$ vapor water per $\mathrm{kg}$ dry air and the specific enthalpy is between 73.8 and $82 \mathrm{~kJ} / \mathrm{kg}$.

\subsection{Electric consumption price:}

In order to balance the daily energy demand of industrial and household consumers, the government of Vietnam classified the time dependence based on timing of energy demanding and proposed the way to measure the electric cost for electric consumption in business and manufacture apart from social household. The electricity prices for business and industrial consumer are set in the working times of the day as shown in Table 1 . The prices are counted based on the interval timing energy consumption with the peak hours, normal hours and low hours. During the peak hours from 10AM to 12AM and 5PM to $8 \mathrm{PM}$, the electric cost is $19.71 \$ \mathrm{sent} / \mathrm{kWh}$. At the low hours from 10PM to 4AM, the price is counted as only $7.14 \$$ cent $/ \mathrm{kWh}$, it is only 0.36 times compared with the peak hours. In the rest time of a day (at the normal hours, the price is $11.46 \$$ cent $/ \mathrm{kWh}$. So, with the policy of depending on time to measure the energy consumption cost, the manufactures should make an operating plan to optimize productions costs. 
Table 1. The industrial prices for electric consumption in Vietnam.

\begin{tabular}{|c|c|c|c|c|c|c|}
\hline \multirow{2}{*}{ Time } & $\mathbf{4 : 0 0} \div \mathbf{1 0 : 0 0}$ & $\mathbf{1 0 : 0 0} \div \mathbf{1 2 : 0 0}$ & $\mathbf{1 2 : 0 0} \div \mathbf{1 7 : 0 0}$ & $\mathbf{1 7 : 0 0} \div \mathbf{2 0 : 0 0}$ & $\mathbf{2 0 : 0 0} \div \mathbf{2 2 : 0 0}$ & $\mathbf{2 2 : 0 0} \div \mathbf{4 : 0 0}$ \\
\cline { 2 - 7 } & $\begin{array}{c}\text { Normal } \\
\text { hours }\end{array}$ & Peak hours & $\begin{array}{c}\text { Normal } \\
\text { hours }\end{array}$ & Peak hours & $\begin{array}{c}\text { Normal } \\
\text { hours }\end{array}$ & Low hours \\
\hline $\begin{array}{c}\text { VND/kWh } \\
(\text { Vietnamdong) }\end{array}$ & 2666 & 4586 & 2666 & 4586 & 2666 & 1662 \\
\hline$\$$ cent/kWh & 11.46 & 19.71 & 11.46 & 19.71 & 11.46 & 7.14 \\
\hline
\end{tabular}

\subsection{Atmospheric water generator system:}

Operating principles: Water vapor in the air can be condensed when the humid air flows through evaporator of VCR system by cooling the air below its dew point. Figure 3 represents the scheme of atmospheric water generator, it can be seen into two cycles, one about refrigerant and other is atmospheric air (humid air). In evaporator, the refrigerant will receive the heat to evaporate from liquid phase into vapor phase at the low pressure which corresponds to the low temperature. The air from the atmosphere will pass through evaporator, due to refrigerant absorbs the heat from air to cool the air at low dew point temperature, and the water vapor from the air will be condensed.

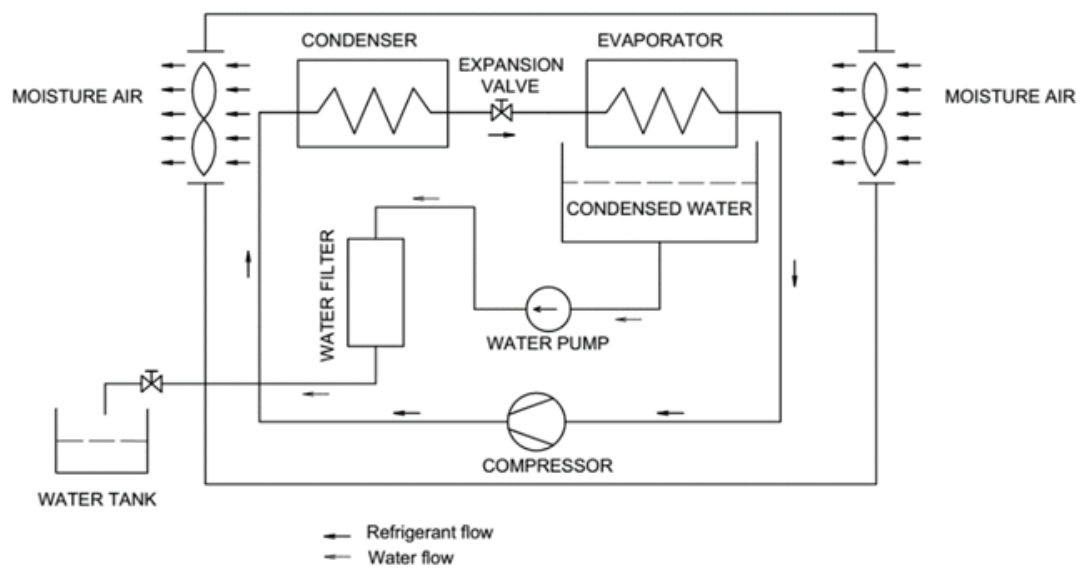

Fig. 3. Scheme of atmospheric water generator system

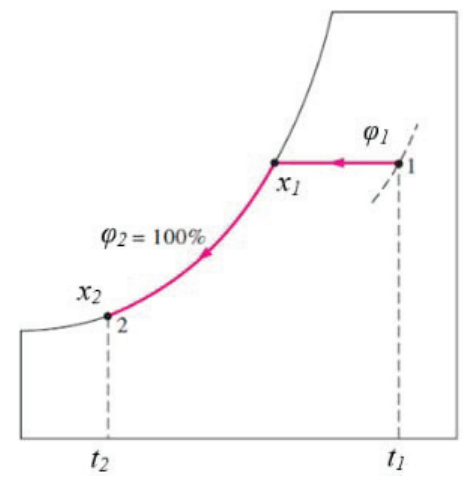

Fig. 4. Diagram of humid air at evaporator. 


\section{Data processing}

The input data which is the weather conditions collected in Danang Province is used to determine the inlet state of moist air of evaporator. The temperature of outlet air from the evaporator is considered to optimize the system. The properties of moist air at the evaporator outlet at saturation state with the range of temperature from 10 to $17^{\circ} \mathrm{C}$ are presented in Table 2.

Table 2. The properties of moist air at the outlet of evaporator.

\begin{tabular}{|c|c|c|c|c|c|c|c|c|c|}
\hline $\mathbf{t}$ & {$\left[{ }^{\circ} \mathrm{C}\right]$} & 10 & 11 & 12 & 13 & 14 & 15 & 16 & 17 \\
\hline $\boldsymbol{\varphi}$ & {$[\%]$} & 100 & 100 & 100 & 100 & 100 & 100 & 100 & 100 \\
\hline $\mathbf{x}$ & {$\left[\mathrm{kg}_{\text {н2о }} / \mathrm{kg}_{\text {air }}\right]$} & 0.0076 & 0.0081 & 0.0087 & 0.0093 & 0.0099 & 0.0106 & 0.0113 & 0.0121 \\
\hline $\mathbf{h}$ & {$\left[\mathrm{kJ} / \mathrm{kg}_{\text {air }}\right]$} & 29.24 & 31.60 & 34.04 & 36.58 & 39.21 & 41.94 & 44.78 & 47.73 \\
\hline
\end{tabular}

Table 3. Notation of air at the inlet and outlet of evaporator.

\begin{tabular}{|c|c|c|c|}
\hline Moist air & Unit & Inlet & Outlet \\
\hline Temperature & {$\left[{ }^{\circ} \mathrm{C}\right]$} & $t_{1}$ & $t_{2}$ \\
\hline Relative humidity & {$[\%]$} & $\varphi_{1}$ & $\varphi_{2}$ \\
\hline Specific humidity & {$\left[\mathrm{kg}_{\mathrm{H} 2 \mathrm{O}} / \mathrm{kg}_{\text {air }}\right]$} & $x_{1}$ & $x_{2}$ \\
\hline Specific enthalpy & {$\left[\mathrm{kJ} / \mathrm{kg}_{\text {air }}\right]$} & $h_{1}$ & $h_{2}$ \\
\hline
\end{tabular}

The mass of air $\mathrm{G}_{\text {air }}$ needed to produce 1 liter of water:

$$
G_{\text {air }}=1 /\left(x_{1}-x_{2}\right) \quad\left[\mathrm{kg}_{\text {air }} / \mathrm{kg}_{\mathrm{H} 2 \mathrm{O}}\right] \text {. }
$$

The cooling load $\mathrm{Q}_{\mathrm{o}}$ needed to produce 1 liter of water:

$$
Q_{0}=G_{\text {air. }}\left(h_{1}-h_{2}\right) \quad\left[\mathrm{kJ} / \mathrm{kg}_{\mathrm{H} 2 \mathrm{O}}\right] \text {. }
$$

The Energy consumption (Electricity) for the production of 1 liter of water:

where EER is Energy Efficiency Ratio.

$$
P=Q_{0} /(E E R .3600) \quad\left[\mathrm{kWh}_{\text {electricity }} / \mathrm{kg}_{\mathrm{H} 2 \mathrm{O}}\right] \text {, }
$$

The cost of producing 1 liter of water:

$$
C=P \cdot p \quad\left[\$ \text { cents } / \mathrm{kg}_{\mathrm{H} 2 \mathrm{O}}\right],
$$

where: $p$ is the price of electricity [\$cents/kWh].

\section{Results and discussion}

The effectiveness of the atmospheric water generator in Danang Province in Vietnam is presented below. Based on the optimization of the air temperature at the evaporator outlet and the schedule for electricity consumption tariffs by Vietnam Government, the study gives a suggestion of water producing efficiency in the appropriate working hours of a day.

\subsection{The influence of outlet temperature of air on the cooling load}

As mentioned above, the analysis would be defined for every month of the year, with the weather data in Danang as input parameters and the changing of outlet temperature of air from 10 to $17^{\circ} \mathrm{C}$. The procedure was repeated for each month from January to December 
and one typical month - July is taken as an example for some figures due to the strong effect on water demand. The changing of cooling load for production of one liter of water is affected by outlet temperature as shows in Figure 5, an increasing of cooling load in the day time and reducing in the night-time for all outlet temperature values. More detailed, when working with 10 to $14^{\circ} \mathrm{C}$, the cooling load could get the good result in the day time, but get worse in the night-time; this trend is also repeated in the other months. To minimize the average value of cooling load for production of one liter of water, the outlet temperature could be chosen at $13^{\circ} \mathrm{C}$. One, due to the consideration of the balancing cooling load between day and night, other, due to the VCR system for AWG, the boiling refrigerant inside the evaporator should get temperature higher than $0^{\circ} \mathrm{C}$ to avoid the frost formation on the surface of evaporator, so it could operate around $5^{\circ} \mathrm{C}$. In order to get the best heat transfer between refrigerant inside and air flow outside of evaporator, the temperature of air at the outlet of evaporator could be reduce to lowest around 12 to $14^{\circ} \mathrm{C}$.

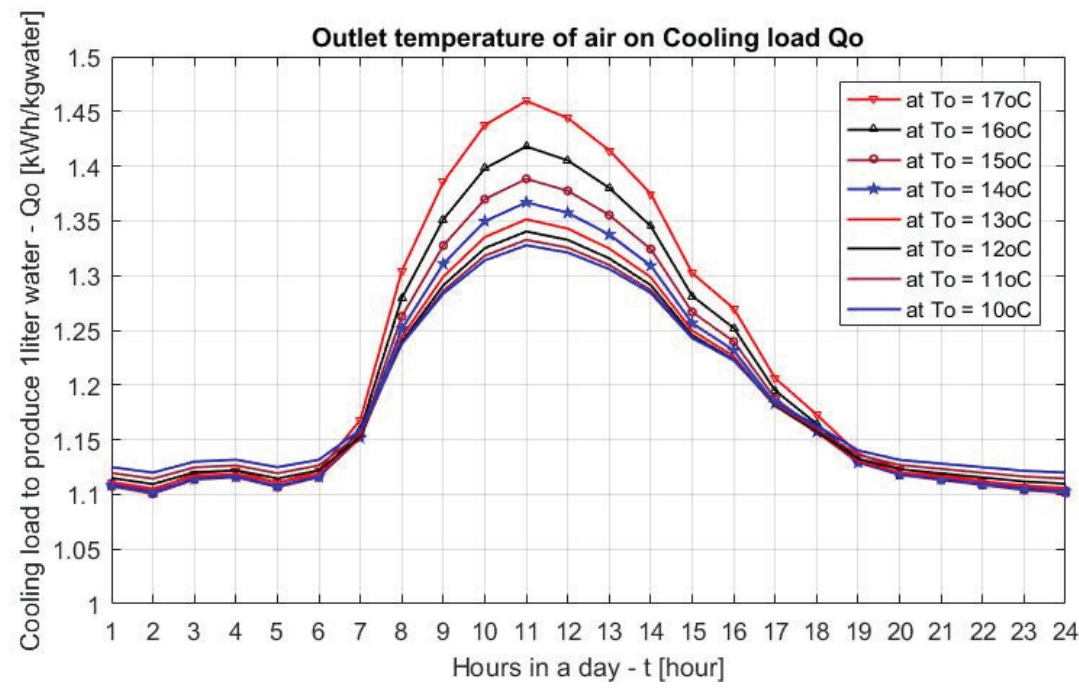

Fig. 5. The influence of the different outlet temperature on the cooling load in July.

So, the air temperature at the evaporator outlet is determined $13^{\circ} \mathrm{C}$. In Figure 6 , the cooling load at $13^{\circ} \mathrm{C}$ working for all months from January to December is represented. The lowest cooling load is on October and the highest is on January.

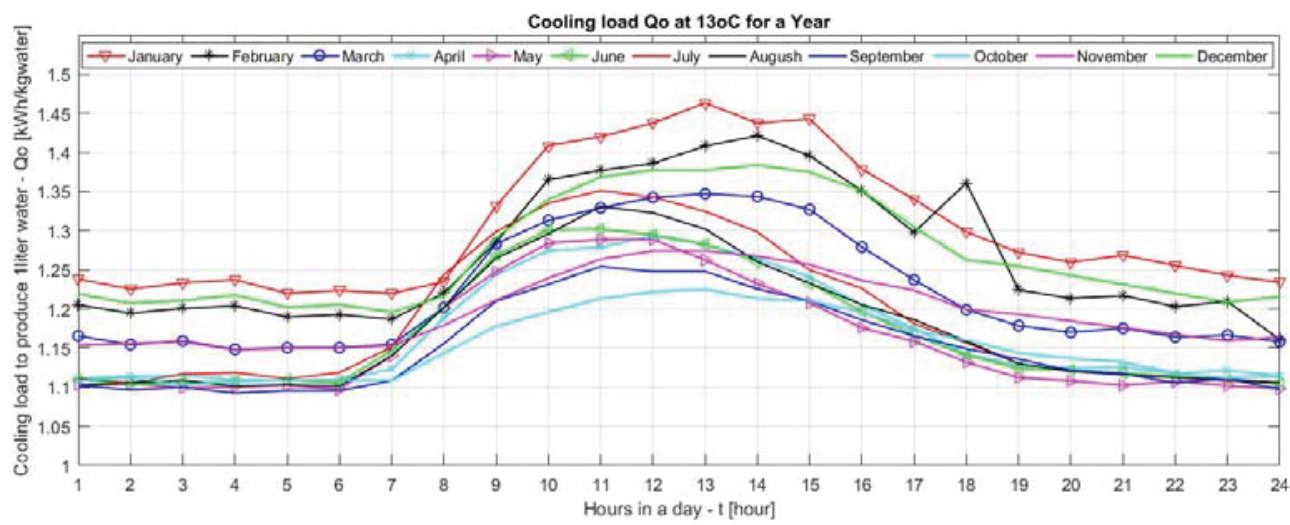

Fig. 6. The cooling load at outlet temperature $13^{\circ} \mathrm{C}$, depending on the time. 


\subsection{The effect of the electricity prices in Vietnam on the production costs of water}

The net electric consumption for production of one-liter water is determined by the cooling load and the energy efficiency ratio (EER) of the VCR system. The average value of EER for vapor-compression refrigeration systems in the current trading market in Vietnam is around 4 to 6 , in this case, EER $=4.5$ was chosen.

Depending on the price of electricity (peak hours, normal hours and low hours on Table 1) and cooling load analyzed above, the production cost per one liter of water is calculated for all months in Danang, Vietnam. The data results are presented in Figure 7, it is clearly observed that at the peak hours, the price to produce one-liter water is very expensive, it is around 5.5 cents, nearly twice compare with the normal hours and more than 3.5 times compare with low-price hours.

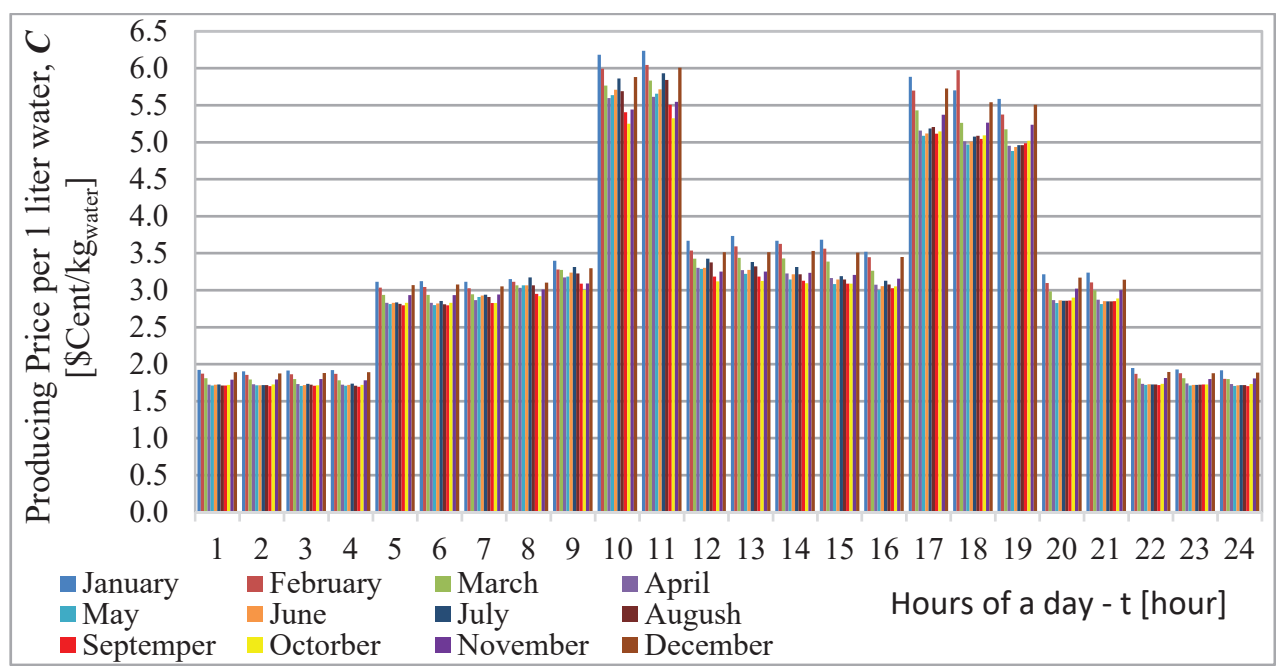

Fig. 7. The production price per liter of water, depending on the time.

\subsection{The case studies related to the working time intervals}

As presented above about the price of electricity, the manufactures should analyze their operating plan to optimize productions costs. In this research, the optimization is considered by classification into four case studies for four different purposes:

- Case 1: The atmospheric water generator system works the whole day;

- Case 2: The AWG system works the whole day, except the peak hours;

- Case 3: The AWG system works during the hours with the lowest cooling load;

- Case 4: The AWG system works on the lowest-price hours.

The production cost for one liter of water is very different in those cases. In Figure 8, the cooling load and production price are indicated for every month of a year when the AWG system operates for a whole day. The production price is estimated at $3 \div 3.5$ cents $/ \mathrm{kg}_{\text {water }}$. If the AWG system is stopped only at the peak hours, the production cost per liter of water is about 2.5 to 3 cents $/ \mathrm{kg}_{\text {water, }}$ as shown in Figure 9. With the purpose for the lowest cooling load, the system works in the time interval from 20:00 to 7:00, and the price is about $2.3 \div 2.5$ cents $/ \mathrm{kg}_{\text {water }}$ (Figure 10). The case of the lowest-price hours, from 20:00 to 4:00, is shown in Figure 11, the producing price is less than 2 cents $/ \mathrm{kg}_{\text {water }}$. The cases in which the price is less than 2 cents and 2.3-2.5 cents are very good results for the production of water from atmospheric air in Vietnam. 


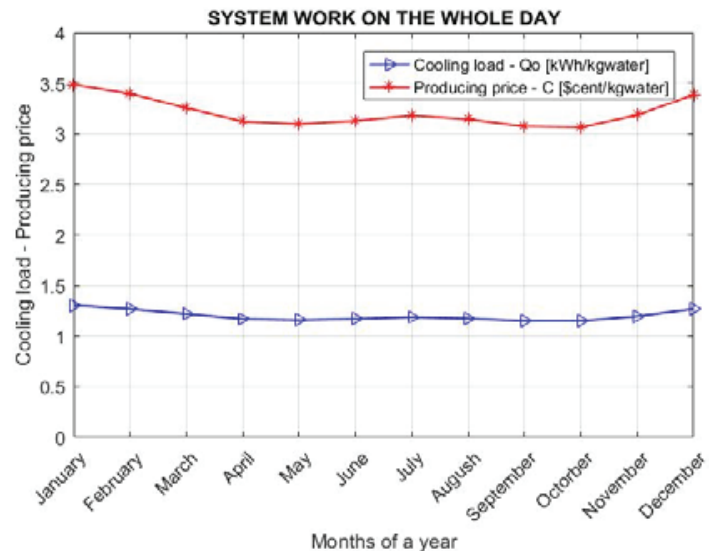

Fig. 8. Case 1-AWG works the whole day.

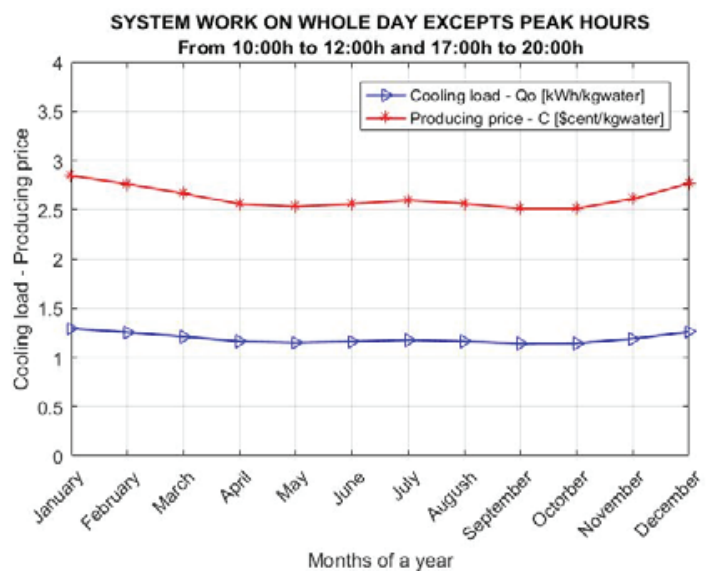

Fig. 9. Case 2-AWG works the whole day except peak hours.

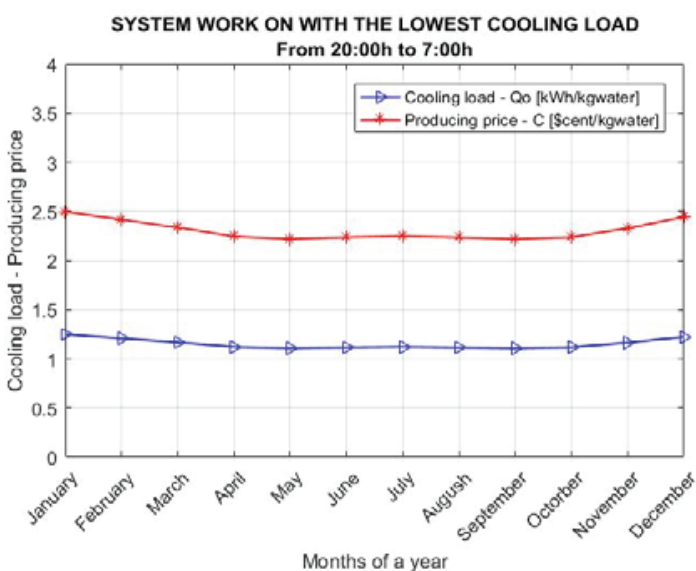

Fig. 10. Case 3 - AWG works the lowest cooling load. 


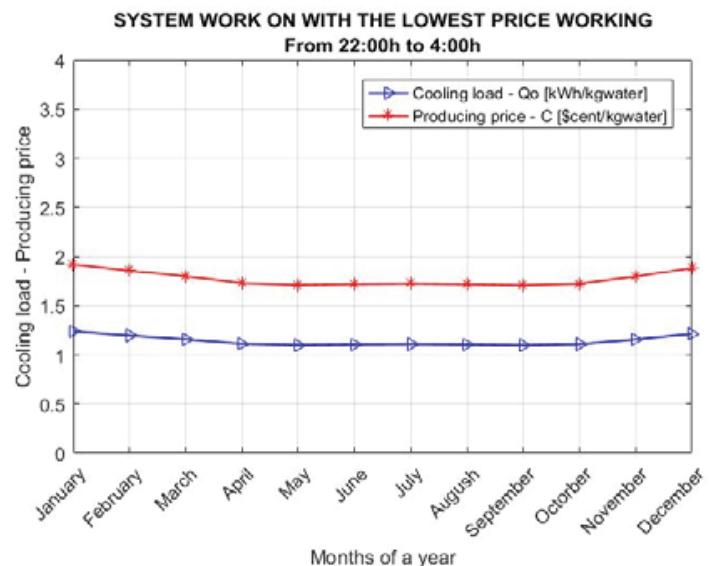

Fig. 11. Case 4 - AWG works on the lowest-price hours.

\section{Conclusions}

In conclusion, this paper has solved the following problems:

- Evaluates the behavior of the cooling load $Q_{0}$ variation in the day;

- Evaluates the influence of outlet air temperature on $\mathrm{Q}_{0}$;

- Provides a preliminary assessment of electricity costs to produce one litter of water at different hours in a day; from which gives a suggested working plan.

There is still much room for other researches in the field of air-based water production:

- Evaluates the impact of EER (Energy Efficiency Ratio) when air flow out of the evaporator to release the heat in condensation process;

- Evaluates the economic efficiency, equipment cost, total cost per litter of water;

- Experimental testing the results of other theoretical studies.

We would like to thank Ho Chi Minh City University of Technology (HCMUT), VNU-HCM for the support of time and facilities for this study.

\section{References}

1. A. Magrini, L. Cattani, M. Cartesegna, L. Magnani, Production of water from the air : the environmental sustainability of air-conditioning systems through a more intelligent use of resources. The advantages of an integrated system, Energy Procedia, 78, pp. 1153-1158, (2015)

2. B. Hellstrom, Potable water extracted from the air report on laboratory experiments, J. Hydrol., 9, pp. 1-19, (1969)

3. T. Anbarasu, S. Pavithra, Vapour compression refrigeration system generating fresh water from humidity in the air, International Conference on Sustainable Energy and Intelligent Systems (SEISCON 2011), pp. 75-79, (2011)

4. S. Elshamarka, "Absorption Heat Pump for a Potable Water Supply in a Solar House", Appl. Energy, 40(1), pp. 31-40, (1991)

5. V. P. Joshi, V. S. Joshi, H. A. Kothari, M. D. Mahajan, M. B. Chaudhari, K. D. Sant, Experimental investigations on a portable fresh water generator using a thermoelectric cooler, Energy Procedia, 109, pp. 161-166, (2017) 
6. D. Runze, M. Qingfen, L. Hui, W. Gaoping, Y. Wei, C. Guangfu, C. Yifan, Experimental investigations on a portable atmospheric water generator for maritime rescue, J. Water Reuse Desalination, 10(1), pp. 30-44, (2020)

7. Vietnam Building code, Natural Physical and Climatic data for construction QCXDVN 02: 2015/BXD, (2015) 